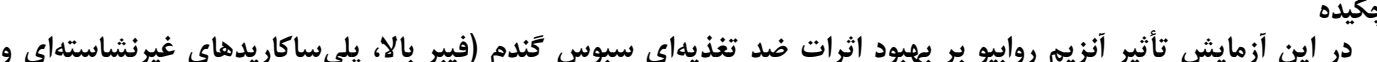

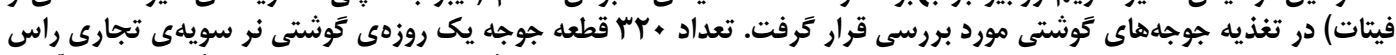

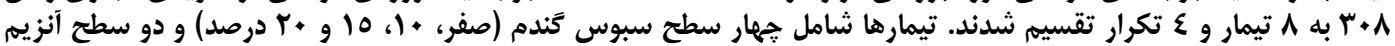

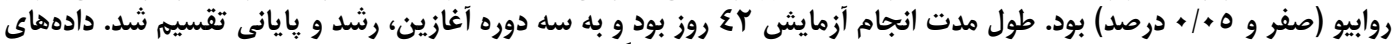

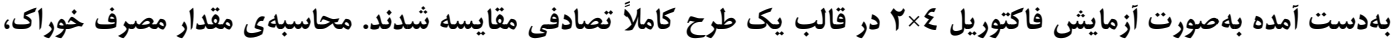

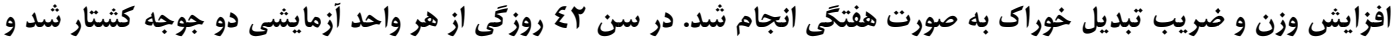

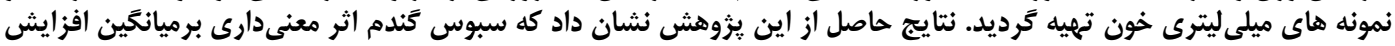

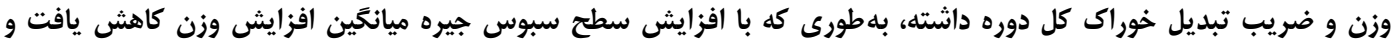

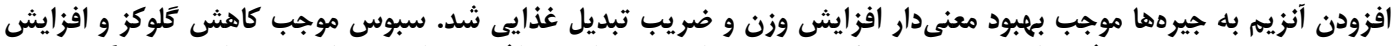

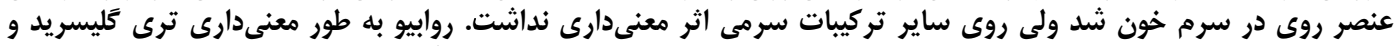

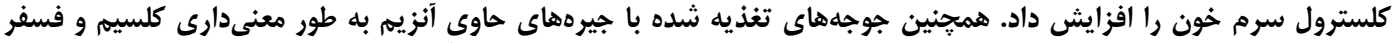

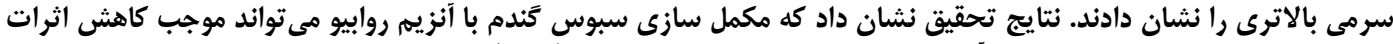

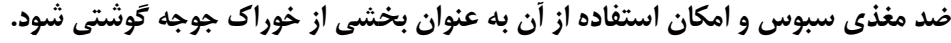

وازههاى كليدى: جوجه تَوشتى، روابيو، سبوس كندم، عملكرد، متابوليتهاى خون

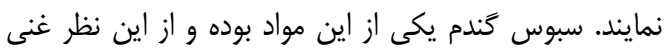

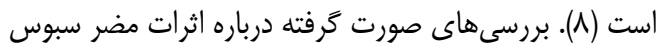

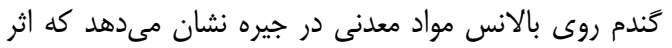

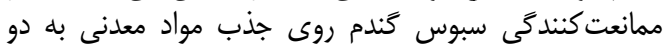

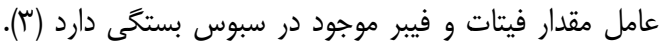

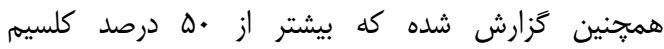

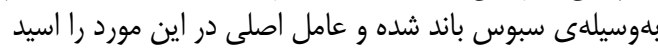

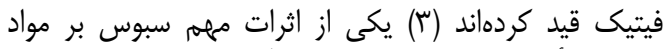

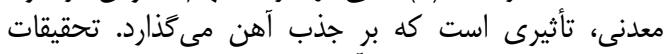

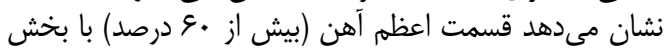

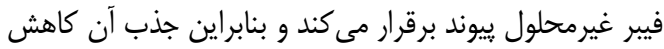

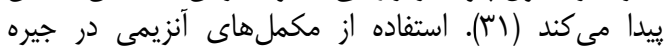

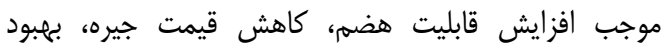

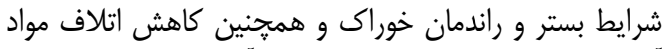

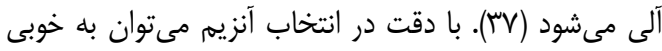

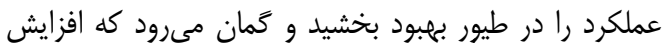
استفاده از آنزيم در غذا، فقط به به دليل منافيل منافع اقتصادى نبوديه،

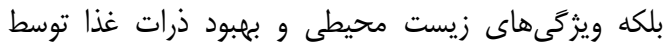

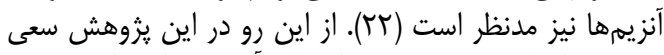

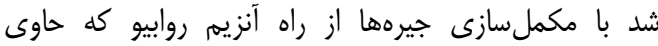

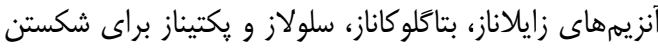

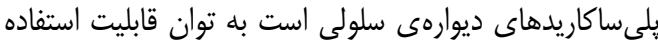

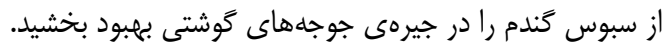

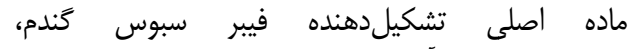

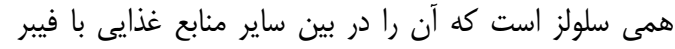

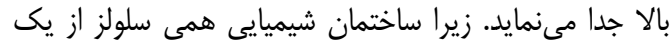

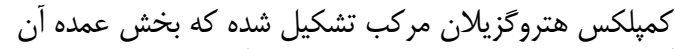

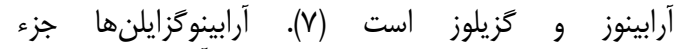

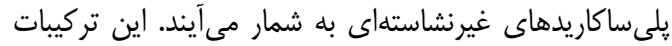

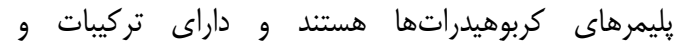

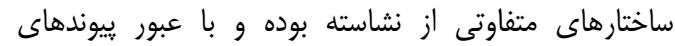

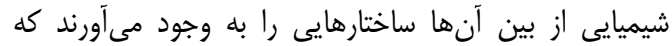

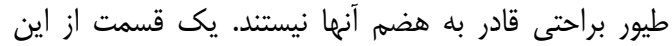

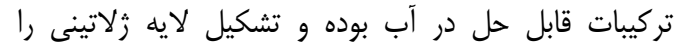

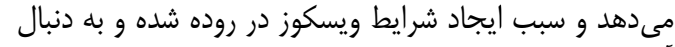

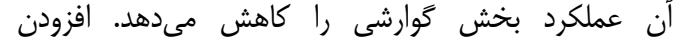

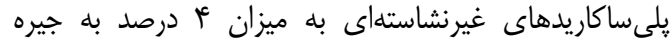

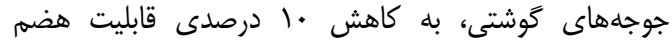

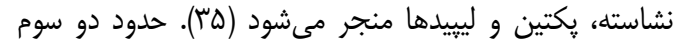

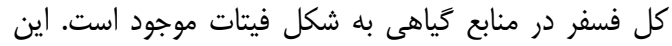

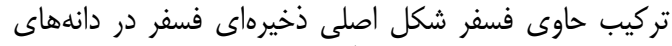

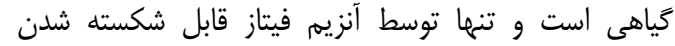

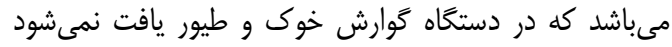

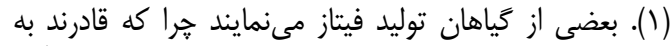

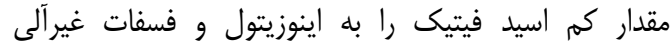
هيدروليز كرده و در نتيجه كاتيونهايى مثل كلسيه رانيت آزاد فينا 
آناليز شدند. مقايسه ميانخينها بر اساس آزمون توكى انجام

نتايج و بحث مصرف خوراك ونى

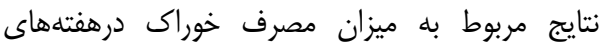

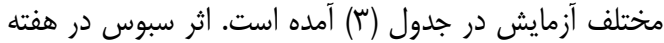

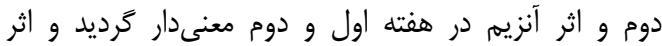

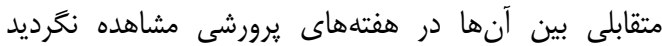

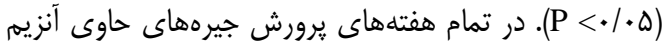

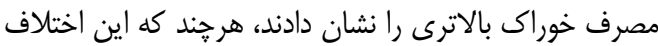

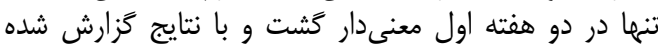

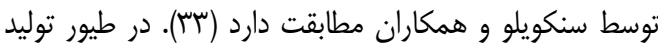

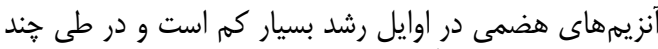

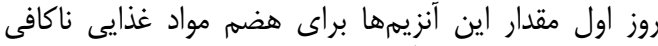

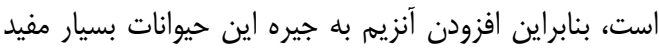

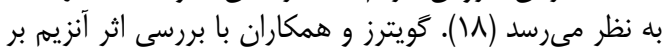

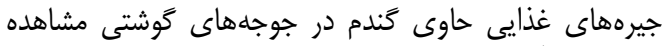

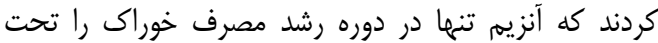

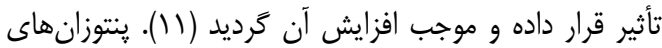

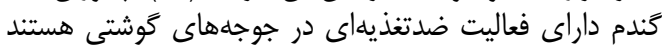

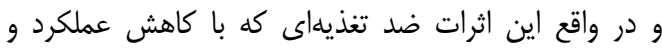

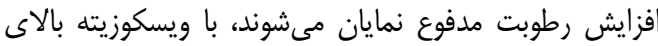

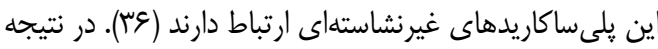

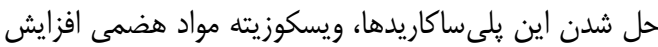

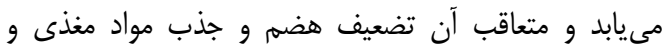

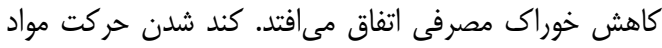

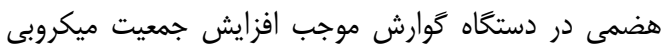

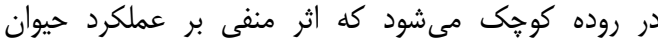

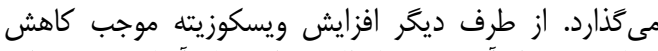

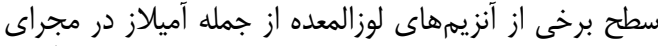

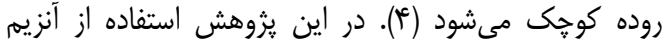

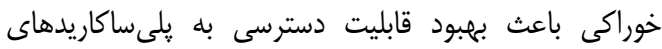

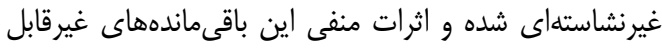

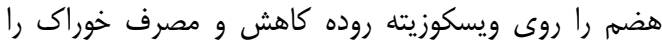
بهبود بخشيد.

\section{مواد و روشهات اجريات}

عمليات اجرايى اين يزوهش دور در تابستان 19 در در سالن

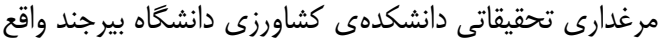

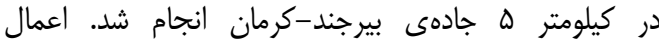

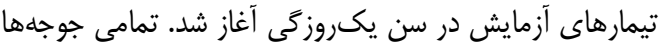

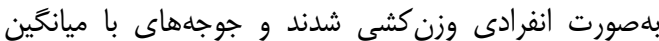

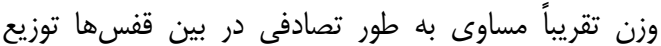

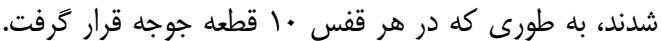

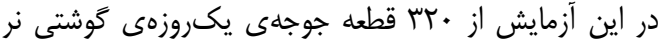

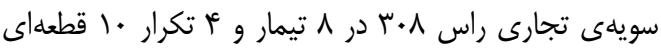

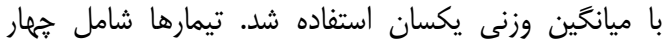

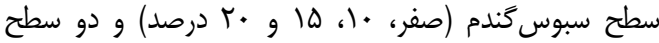

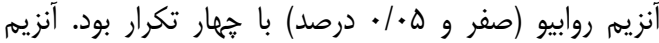

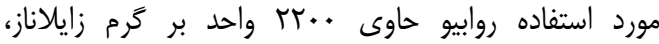

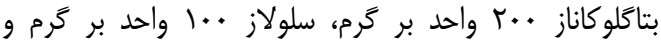

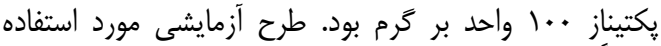

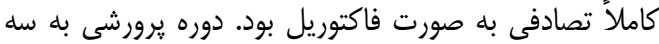

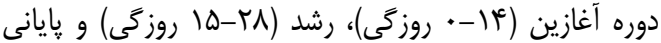

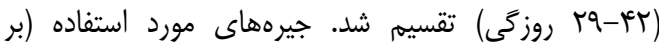

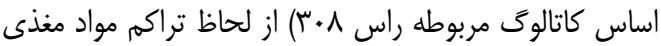

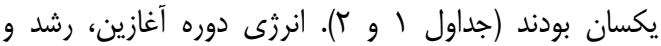

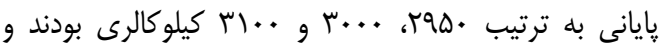

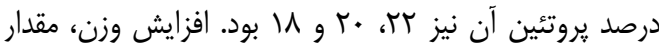

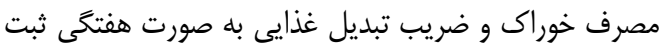

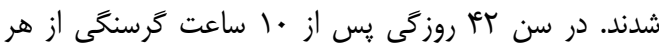

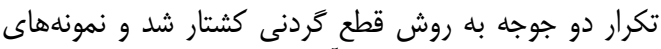

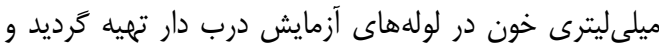

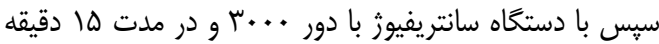

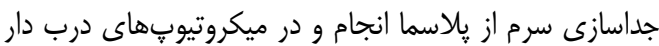

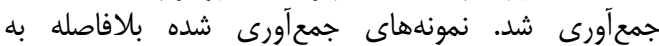

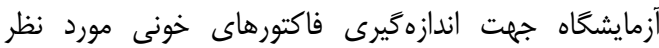

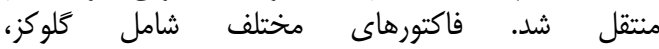

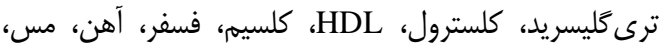

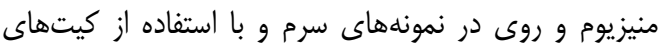

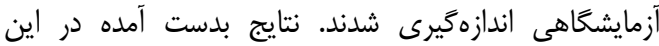

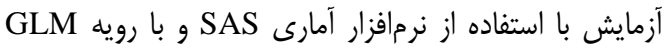


Table 1. Composition of diets without enzyme; starter, grower and finisher

جدول ا- تركيب اجزاى جيرههاى بدون آنزيم آغازين، رشد و پايانى

\begin{tabular}{|c|c|c|c|c|c|c|c|c|c|c|c|c|}
\hline \multicolumn{13}{|c|}{ جيرها | لجا } \\
\hline & \multicolumn{2}{|c|}{ 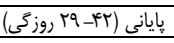 } & \multirow[b]{2}{*}{ - } & \multicolumn{3}{|c|}{ رشد (זی-ها روزگى) } & \multirow[b]{2}{*}{ - } & \multicolumn{4}{|c|}{ أغازين (f(ا-( روزگى) } & \multirow{2}{*}{ سبوس جيره } \\
\hline$r$. & 10 & 1. & & r. & 10 & 1. & & $r$. & 10 & 1. & - & \\
\hline FN/ & $\Delta F / V q$ & $91 / 8$ & $V T / \& A$ & $F \psi / V \Lambda$ & $\Delta V / T r$ & $\Delta N / 1$ & $99 / \pi \mu$ & $r N \cdot r^{r}$ & $\kappa / 1 f$ & $\Delta / / 9 D$ & gr/If & \\
\hline $19 / . *^{e}$ & $r . / \% q$ & $r \cdot / \mathcal{A S}$ & $r T / N^{*}$ & W/V. & $19 / \cdot F^{c}$ & $19 / \mathbb{e q}^{\mathrm{V}}$ & re & $T V / \& \Lambda$ & $r \Delta / 9 q$ & KN/FD & TN/VQ & كنجاله سويا \\
\hline r & $1 / 4$ & $1 / 4$ & 1 & $\Delta$ & $\Delta$ & $\Delta$ & $r / \Lambda$ & $r / \Delta$ & $\Delta$ & $r / \Delta$ & $r / \Delta$ & يودر ماهى \\
\hline$V / \Delta$ & $\Delta / \Lambda$ & $r / \Delta$ & - & $V / q$ & $9 / 1$ & $r / \Delta$ & - & $\mathrm{V} / \mathrm{V}$ & $\Delta$ & $r / r$ & - & روغن \\
\hline $1 / 49$ & 1/9 & $1 / \Delta$ & $1 / 49$ & $1 / \Delta t$ & $1 / 40$ & $1 / F r$ & $1 / \% \Lambda$ & $1 / \Delta \mu$ & $1 / 4 r$ & $1 / 4$ & $1 / r \Lambda$ & صدف \\
\hline $1 / \pi r$ & . / r & $\cdot / A f$ & $1 / r r$ & 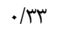 & $\kappa r /$. & $\cdot / \Delta \Delta$ &.$/ 199$ & $\cdot / M$ & $\cdot / \Lambda \Delta$ & 1/1 & $1 / \mathrm{r}^{\prime}$ & دى كلسيم فسفات \\
\hline.$/ 1$ &.$/ 1$ &.$/ 1$ & . 1 & $\cdot / \pi \Delta$ & 看 & $\cdot / T \Delta$ & . $/$ TD & $\cdot / \pi \Delta$ & / TS & . /Rs & . /TD & مكمل مينراله \\
\hline - & - & - & ./va & $\cdot / \pi \Delta$ & . $/ \pi \Delta$ & $\cdot / \pi \Delta$ &.$/ T \Delta$ & $\cdot / \pi \Delta$ & $\cdot / r \Delta$ & . /RD & $\cdot / R \Delta$ & نمى \\
\hline$\cdot / r$ &.$/ r$ &.$/ \pi$ & $\cdot / r$ & $\cdot / r$ &.$/ 4$ & $\cdot / \pi$ &.$/ r$ &.$/ r$ &.$/ r$ & $\cdot / r$ & $\cdot / r$ & دى- ال- متيونين \\
\hline . / & - & - & - & $1 / \cdot \Delta$ & $1 / r$ & $1 / 49$ & - & - & $\cdot / r$ & - & $\cdot /\left.\Delta\right|^{\circ}$ & ال-ليزين \\
\hline- & - & - & - & - & - & - & - & - & - & - & $1 / N 1$ & سنكريزه \\
\hline \multicolumn{3}{|c|}{ يإيانى } & & \multicolumn{3}{|c|}{ ر رشد } & & \multicolumn{4}{|c|}{ أغازين } & تركيب شيميايى \\
\hline rr.. & r.. & r... & rr. & $M I \Delta$. & MIQ. & $\mu \Delta$. & MIQ. & rqه. & rqब. & rqه. & rqه. & (كيلو كالرى قابل در كتيلوكَرم) \\
\hline 11 & M & 11 & 11 & $r$. & $r$. & r. & r. & r & $r$ & $r$ & $r$ & يروتئين (درصد) \\
\hline.$/ 9$. &.$/ 9$. &.$/ 9$. & . $/ 9$. &.$/ 94$ &.$/ 94$ & . /9T & ./9T & $1 / \cdot \cdot$ & $1 / \cdot \cdot$ & $1 / \cdot \cdot$ & $1 / \cdot \cdot$ & كلسيم (درصد) \\
\hline . & •/ ז^ & . & 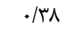 & $\cdot / 4$ & $\cdot / 4$ &.$/ 4$. &.$/ 4$. & $\cdot / \Delta$ & $\cdot / \Delta$. & $\cdot / \Delta$ & $\cdot / \Delta \cdot$ & فسفرقابل دسترس (درصد) \\
\hline.$/ 19$ &.$/ 1 \Lambda$ & .119 &.$/ 1 \Lambda$ & $\cdot / 19$ &.$/ \mathrm{V}$ & $\cdot / 1 \Delta$ &.$/ 11$ & .119 &.$/ 9$ &.$/ 10$ &.$/ 1 f$ & سديم (درصد) \\
\hline $1 / .9$ & $1 / \cdot r$ & $1 /$. &.$/ 9$ & $1 / .9$ & $1 / v$. & $1 / 1 f$ & $1 / . \Delta$ & $1 / 49$ & $1 / F \mathrm{~V}$ & $1 / \Delta 1$ & $1 / 49$ & آررزنين (درصد) \\
\hline.$/ 9$ &.$/ 9$ & $\cdot / \Lambda$ &.$/ 9$ & $1 / \pi r$ & $1 / r$ & $1 / \cdot \Delta$ & $1 / 1$ & $1 / 49$ & $1 / \% 9$ & $1 / \pi T^{2}-1-1$ & $1 / 49$ & ليزين (درصد) \\
\hline .199 &. $\mid 9 \Lambda$ &.$/ 94$ &.$/ 94$ & .199 & .191 &.$/ 9 y^{6}$ & $\cdot / N r$ &.$/ 91$ & $\cdot / M$ &.$/ 19$ &.$/ 95$ & متيونين + سيستئين (درصد) \\
\hline$\cdot / \Delta \Lambda$ & . $/ \Delta T$ &.$/ 49$ & $\cdot / \Delta \Delta$ & $\cdot \mid 9 \Lambda$ & . $/ 94$ &.$/ N r$ & .9. & $\cdot / M$ & - / $\triangle \Delta$ & -/AV & $\cdot / 199$ & ترئونين (درصد) \\
\hline.$/ 14$ & .110 &.$/ 1 f$ & ./1f & $\cdot / \Lambda$ &.$/ \mathrm{V}$ &.$/ 19$ &.$/ \mathrm{V}$ &.$/ 4 V$ & . &.$/ 4 q$ & $\cdot / T r$ & ترييتوفان (درصد) \\
\hline
\end{tabular}

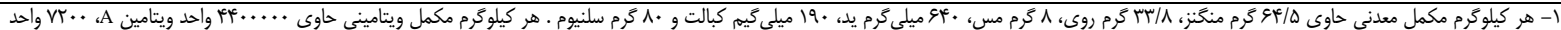

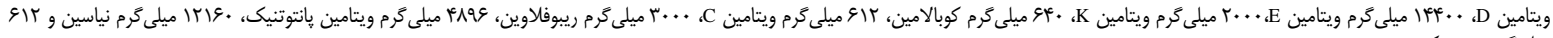

ميلى كرم بييرودوكسين.

Table 2. Composition of diets with enzyme; starter, grower and finisher

جدول r- تركيب اجزاى جيرههاى حاوى آنزيم آغازين، رشد و پايانى

\begin{tabular}{|c|c|c|c|c|c|c|c|c|c|c|c|c|}
\hline \multicolumn{12}{|c|}{ جيرهها } & \multirow{3}{*}{ سبوس جيره } \\
\hline \multicolumn{4}{|c|}{ 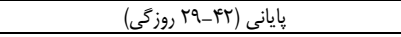 } & \multicolumn{4}{|c|}{ 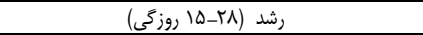 } & \multicolumn{3}{|c|}{ آغازين (ז)-( روزگى) } & \multirow[b]{2}{*}{ - } & \\
\hline$r \cdot$ & 10 & 1. & - & r. & 10 & 1. & - & r. & 10 & 1. & & \\
\hline F & $\Delta F / V G$ & $81 / 8$ & $V T / F r$ & $F F / v \wedge$ & $\Delta 1 / r$. & $\Delta N /+9$ & sq/rr & TV/AT & $\notin \varepsilon / I V$ & DI/DT & gr/IF & ذرت \\
\hline$r \cdot / / r$ & $r \cdot / r$. & $r \cdot / g r$ & tr/VF & W/ED & W/QG & $19 / 4$ & rq/. & $\mathrm{rV} / \mathrm{V}$. & $r \Delta / \Delta r$ & $r N / F A$ & KN/VD & كنجاله سويا \\
\hline$\cdot / \cdot \Delta$ &.$/ . \Delta$ &.$/ . \Delta$ &.$/ \cdot \Delta$ & $\cdot / \cdot \Delta$ & $\cdot / \cdot \Delta$ &.$/ \cdot 0$ & $\cdot / \cdot 0$ & $\cdot / \cdot \Delta$ & $\cdot / \cdot \Delta$ & $\cdot 1 \cdot 0$ & $\cdot / \cdot \Delta$ & آنزيم' \\
\hline $1 / 8$ & $1 / 8$ & $1 / 8$ & 1 & $\Delta$ & $\Delta$ & $\Delta$ & $r / \Lambda$ & $r / \Delta$ & $\Delta$ & $\Gamma / \Delta$ & $r / \Delta$ & يودر ماهى \\
\hline$V / \Delta$ & $\Delta / \Lambda$ & $\Gamma / \Delta$ & - & $V / q$ & $8 / 1$ & $r / \Delta$ & - & $\mathrm{V} / \Lambda$ & $\Delta$ & $r / r$ & - & 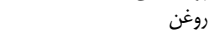 \\
\hline V/Dr & $1 / 8$ & $1 / \Delta$ & $1 / 48$ & V/DF & $1 / \leftarrow \wedge$ & $1 / 4 T$ & $1 /{ }^{\prime}$ & $1 / \Delta \Delta$ & $1 / 4$ & Tאוא & $1 / T \Lambda$ & صدف \\
\hline $1 / . r$ &.$/ 99$ & . /Ar & r/T & 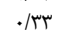 & $\kappa \% \%$ &.$/ \Delta \Delta$ &.$/ 19$ &.$/ M$ &.$/ 18$ & $1 / 1 T$ & $1 / \%$ & دى كلسيم فسفات \\
\hline$\cdot / 1$ &.$/ 1$ & $\cdot / 1$ & $\cdot / 1$ &.$/ T \Delta$ &.$/ T \Delta$ &.$/ T \Delta$ &.$/ T \Delta$ &.$/ T \Delta$ &.$/ T \Delta$ &.$/ T \Delta$ &.$/ T \Delta$ & مكمل مينراله و ويتامينه'r \\
\hline- & - & - &.$/ \mathrm{vq}$ &.$/ K \Delta$ &.$/ T \Delta$ &.$/ T \Delta$ &.$/ T \Delta$ &.$/ T \Delta$ &.$/ K \Delta$ &.$/ T \Delta$ &.$/ T \Delta$ & 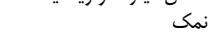 \\
\hline$\cdot / r$ & $\cdot / r$ & $\cdot / r$ & $\cdot / r$ & $\cdot / 4$ & $\cdot / r$ & $\cdot / 4$ & $\cdot / r$ & $\cdot / 4$ & $\cdot / r$ & $\cdot / r$ & $\cdot / r$ & دى-ال-متيونين \\
\hline.$/ 14$ & - & - & - & $1 / \cdot 0$ & $1 / r$ & 1/4 & - & - &.$/ 4 q$ & - &.$/ D F$ & ال-ليزين \\
\hline- & - & - & - & - & - & - & - & - & - & - & $1 / 99$ & سنكر يزه \\
\hline \multicolumn{3}{|c|}{ بِايانى } & & \multicolumn{3}{|c|}{ ر رشد } & & \multicolumn{4}{|c|}{ آغازين } & تركيب شيميايى \\
\hline rr... & rr.. & rr.. & rr.. & MIQ. & MIQ. & TID. & MID. & rqQ. & rqD. & rqa. & raD. & (كيلوكالرى در كابل متابوليسمرم) \\
\hline 11 & 11 & 11 & 11 & r. & r. & r. & r. & tr & tr & tr & tr & يروتئين (درصد) \\
\hline$\cdot / 9$ &.$/ 9$ &.$/ 9$. &.$/ 9$ &.$/ 94$ &.$/ 94$ &.$/ 94$ &.$/ 94$ & $1 / \cdot$ & $1 / \cdot$ & $1 / \cdot$. & $1 / \cdot$ & كلسيم (درصد) \\
\hline 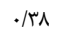 & . & $\cdot / \kappa$ & $\cdot / \kappa$ & $\cdot / 4$ & $\cdot / 4$ & $\cdot / 4$ &.$/ 4$ &.$/ 0$ & $\cdot / 0$ &.$/ 0$ &.$/ \Delta$ & فسفرقابل دسترس (درصد) \\
\hline$\cdot / 1 \wedge$ &.$/ \mathrm{V}$ &.$/ 19$ & $\cdot / 1 \Lambda$ &.$/ 19$ &.$/ \mathrm{VV}$ & $\cdot / 10$ &.$/ 11$ &.$/ 19$ &.$/ 1 f$ &.$/ 10$ &.$/ 19$ & سديم (درصد) \\
\hline $1 / \cdot r$ & $1 / \cdot f$ & $1 / 1$ &.$/ 9$ & $1 / .9$ & $1 / v$ & $1 / 1 f$ & $1 / \cdot \Delta$ & $1 / 4 V$ & $1 / \infty 1$ & $1 / 49$ & $1 / 49$ & آرثنين (درصد) \\
\hline.$/ 9$ &.$/ 9$ & $\cdot / 1$ &.$/ 9$ & שי & $1 / 10$ & $1 / \cdot \Delta$ & $1 / 1$ & $1 / 44$ & $1 / T F$ & $1 / 49$ & $1 / 49$ & ليزين (درصد) \\
\hline .189 & $\cdot / 9 \Lambda$ &.$/ 94$ &.$/ 94$ &.$/ 99$ &.$/ 9 \Lambda$ & $\cdot / 09$ &.$/ V r$ & ./AV &.$/ 19$ &.$/ 94$ &.$/ 91$ & متيونين + سيستئين (درصد) \\
\hline$\cdot / \Delta \Lambda$ & . $/ \Delta{ }^{\prime}$ &.$/ 49$ & $\cdot / \Delta \Delta$ & $\cdot / 8 \Lambda$ &.$/ 94$ & $\cdot / \mathrm{V} \Lambda$ &.$/ 4$ & . /AF & . &.$/ 19$ & $\cdot / M$ & ترئونين (درصد) " \\
\hline.$/ 1 F$ &.$/ 1 \Delta$ &.$/ 1 F$ &.$/ 1 F$ &.$/ 11$ &.$/ 11$ &.$/ 19$ &.$/ 1 V$ &.$/ 4 q$ &.$/ 4 q$ &.$/ T V$ &.$/ T V$ & ترييتوفان (درصد) \\
\hline
\end{tabular}

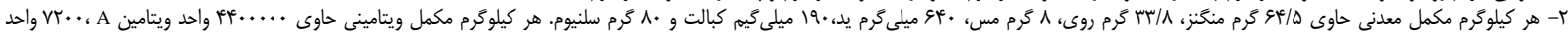

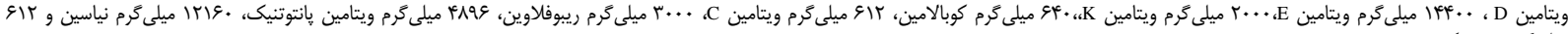


جدول ب- ميانكين مصرف خوراك جوجهها در هفتهاى مختلف و كل مدت آزمايش (جوجه/ گرم) Table 3. Average Feed intake of chicks during the different weeks and entire experimental period (chicken / g)

\begin{tabular}{|c|c|c|c|c|c|c|c|}
\hline \multicolumn{8}{|c|}{ اثر آنزيم } \\
\hline كل دوره & هفته ششم & هفته ينجم & هفته جهارم & هفته سوم & هفته دوم & هفته اول & \\
\hline rAVQ/AI & ITVN/QT & $1 . .9 / V T$ & $V \cdot 9 / 9)^{4}$ & $\Delta 1 N / 19$ & $T F \Delta / \Delta q^{D}$ & $11 \cdot / 44^{D}$ & صفر \\
\hline$r 9 \Delta N / \Delta T^{2}$ & ITTD/TT & $1 . r N / 19$ & $n 1.1 \cdot 9$ & DTQ/r & $r \Delta \mu / \Lambda r^{a}$ & $\| \Delta /\left.A\right|^{a}$ & هـ/• درصد \\
\hline IT/qV. & 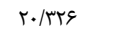 & $v / 9.9$ & $r /$ rqf & $r / N r \Delta$ & $r / \cdot V r$ & $1 / 494$ & اشتباه معيار ميانگين \\
\hline \multicolumn{8}{|c|}{ اثر سبوس } \\
\hline raro//1 & $1790 / 94$ & $1 . T r / \Delta$. & $V I N / F^{4}$ & $\Delta T \Delta /{ }^{\prime} \Lambda$ & $\operatorname{TQT} / .^{\mathrm{a}}$ & $11 . / 94$ & صفر \\
\hline rqท//q & Irrq/दq & I. & $V \mid \varepsilon / .$. & $\Delta T N / F T^{+}$ & $r \Delta r / \Lambda)^{a}$ & $114 / 89$ & ا. \\
\hline ا ו & ITVV/VA & $1 . . r / \cdot 9$ & $\vee \cdots / r \Lambda$ & $\Delta I N / V Q$ & $r \Delta T / .^{a}$ & $\| \Delta / r \Lambda$ & هادرصد \\
\hline$r q . \Delta / r \Delta$ & IrTr/qF & $1.10 / 94$ & $s q 9 / r \Delta$ & $\Delta I F / \Delta F$ & $r F I / . q^{D}$ & $111 / \Delta$. & ك r درصد \\
\hline W/ra. & TN/VES & $11 / \backslash \wedge \Delta$ & g/rif & 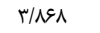 & ( ) & $r / \cdot V I$ & اشتباه معيار ميانكين \\
\hline \multicolumn{8}{|c|}{ اثر متقابل آنزيم × سبوس } \\
\hline TNEF/VQ & $I T \Delta V / V \Delta$ & $1.11 / \mathrm{r \Lambda}$ & $\mathrm{VIS/ \mu \Lambda}$ & $\Delta T I / V Q$ & $r+q / \Delta$. & $1+N / \cdot$ & קِايه بدون سبوس \\
\hline ए৭ఎ१/rЬ & אותודזו & 1.rV/IT & VIV/Ta & $\Delta T F / T H$ & $r+q / I r$ & $11 \cdot / 0$ & •ا درصد سبوس \\
\hline TVNE/AV & ( & $914 / 1 r$ & द91/VQ & $\Delta \mid \varepsilon /{ }^{\prime} \Lambda$ & TE\&/M & س & ها درصد سبوس \\
\hline ГА१९/rV & ITY/VD & $1 . .9 / T \Delta$ & $V \cdot r / r \Lambda$ & $\Delta 1 . / \Delta$. & ITK/FD & $1.9 / 8 \pi$ & • • م درصد سبوس \\
\hline TQR०/दर & 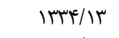 & 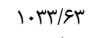 & $V T \cdot / 0$. & orq/.. & rAT/D. & $11 r / M$ & بدون سبوس+آنزيهم \\
\hline rakf/gr & ITTN/TD & I. MT/D. & $V I F / V Q$ & $\Delta T r / V \Delta$ & TAN/D. & $11 N / M$ & •ا درصد سبوس + آنزيم. \\
\hline$r q \uparrow \Delta / v \Delta$ & 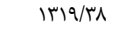 & $1 \cdot r T / . \cdot$ & $v \cdot q / .$. & QTI/IT & $r \Delta V / I T$ & $11 V / 1 \%$ & ها درصد سبوس +آنزيم \\
\hline एवाN/IT & 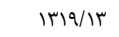 & 1.rQ/gr & sqs/lr & $\Delta \mid N / F T$ & $T F \Delta / T_{D}$ & ي ג & • ب درصد سبوس+آنزيم \\
\hline rr/qr. & $|F /| r \wedge$ & ه/द99 & r/T\&G & $r / \cdot V \cdot$ & $1 / V Q 1$ & M.r & اشتباه معيار ميانكًين \\
\hline \multicolumn{8}{|c|}{ سطوح معنى دارى } \\
\hline$\cdot / 14 \ldots$ & $\cdot / T \cdot V \cdot$ & .1 .999 & . $/$ gIET &.$/ \cdot V T \Delta$ & .1 .998 & .1 .109 & أنزيم \\
\hline $.109 \ldots$ & $\cdot / \Delta \Delta M$ & $\cdot / r \vee \& \Delta$ & $.1 \cdot V r$. &.$/ \cdot V \Delta \Delta$ & .1 .199 & . THEAV & سبوس \\
\hline$. / v G .$. & - /DFTE & $\cdot / N r V \Lambda$ & $.1099 V$ &.$/ 9 \wedge \Delta 1$ & (aYgr & - /ATAV & آنزيم × سبوس \\
\hline
\end{tabular}

جدول أF- ميانكين افزايش وزن جوجهها در هفتهاى مختلف و كل مدت آزمايش (جوجه/ كرم) Table 4. Average weight gain of chicks during the different weeks and entire experimental period (chicken/g)

\begin{tabular}{|c|c|c|c|c|c|c|c|}
\hline \multicolumn{8}{|c|}{ اثر آنزيم } \\
\hline كل دوره & هفته ششم & هفته ينجمم & هفته يهارم & هفته سوم & هفته دوم & هفته اول & \\
\hline $19 \Delta r / \cdot V^{D}$ & $V \cdot r / \cdot^{D}$ & $F+N / 94^{D}$ & $r G \Delta / \mu F$ & $T M I / \& V^{D}$ & $1 f \cdot / V^{W^{D}}$ & $V * / q^{D}$ & صفر \\
\hline$r \cdot 9 V / \Lambda r^{a}$ & $V r V / r \Delta^{a}$ & $\uparrow \vee q / v q^{a}$ & $|N| / N$ & $r f=/ 9 q^{a}$ & $\mid \ll q / r q^{a}$ & $V N / v^{a}$ & هـ/· درصد \\
\hline S/rT. & Q/००. & $V / V V \Lambda$ & G/rND & $\Delta / \Delta \Delta$ & r/А९૬ & $1 / r V \Lambda$ & اشتباه معيار ميانگين \\
\hline \multicolumn{8}{|c|}{ اثر سبوس } \\
\hline$r \mid r T / V \Lambda^{a}$ & $V \& g /\left.F^{a}\right|^{a}$ & $\Delta M Y / F I^{a}$ & $r \Lambda \Delta / \& F^{a}$ & rrr/aq & $\mid f V / A f^{a}$ & $V \varepsilon / \Delta)^{a}$ & صفر \\
\hline$T \cdot T Y / \Delta \Delta^{D}$ & $V T r / \cdot r^{D}$ & FEG/GT & $\Gamma \wedge V / \subset q^{a}$ & $r r v / \Delta q$ & $1 \omega \cdot / V e^{a}$ & $\Lambda \cdot / 1 \cdot^{\mathrm{a}}$ & ا ا درصد. \\
\hline $199 \% / \Delta \Gamma^{D}$ & sqv/ru' & $F \Delta I / / T^{D}$ & $\mathrm{r} \mathrm{NV} / \cdot \Lambda^{\mathrm{a}}$ & $T r q / \Delta F$ & $\mid \omega F / \Gamma \Delta^{\mathrm{a}}$ & $\Lambda \cdot / 11^{a}$ & له ا درصد \\
\hline$\backslash \wedge V \Psi / 9 \Delta^{c}$ & $99 \% / 94^{D}$ & FTA/TFE & 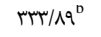 & TrQ/T. & $\mid \mathrm{TV} / \cdot 8^{\mathrm{D}}$ & $99 / 94^{D}$ & • r برصد \\
\hline$N / 94$. & $15 / V 99$ & $1 . / 999$ & १/. & $V / \wedge \notin q$ & $4 / .98$ & $1 / 949$ & اشتباه معيار ميانكين \\
\hline \multicolumn{8}{|c|}{ اثر متقابل آنزيم × سبوس } \\
\hline$r \cdot 9 v / 99$ & $V E I / T \Lambda$ & DTN/TG & TVN/Ar & TIT/MA & $\mid F T / F$ & $V T / V T$ & ريايه بلون سبوس \\
\hline $198 V / r T$ & $V \cdot N / F r$ & FTI/Ir & $r v a / v \wedge$ & TYN/VI & IFT/AF & $V G / 4 g$ & •ا درصد سبوس. \\
\hline $191 \% / 99$ & $9 N \varepsilon / 91$ & fIN/gr & ऍN|/. & TTV/GN & $|\Delta Q / F|$ & VV/AV & ها درصد سبوس \\
\hline MYYF/TA & $901 / \% q$ & fIV/VR & MTI/.g & TIE/ET & $\mid T r / 9 D$ & gq/ar & • r درصد سبوس \\
\hline 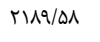 & $W V / \Delta F$ & $\Delta F \cdot / \Delta \Delta$ & rqr/\&ם & roT/l. & $\mid \Delta r / \& \Delta$ & V9/r) & بدون سبوس+آنزيم \\
\hline$r+11 / r V$ & VTD/gr & FET/II & r৭ब/r. & $r \in E / 4 A$ & $\mid Q N / g F$ & Nץ/Vr & • ا درصد سبوس+آنزيم. \\
\hline$r+\Lambda \varepsilon / r q$ & $V \in \Psi / T V$ & 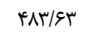 & rqT/4q & 槜 & $\mid Q T / K \Lambda$ & G & ها درصد سبوس+آنزيم \\
\hline $191 \% / 84$ & $99 / 98$ & FrT/VE & reg/VT & & 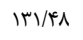 & $s q / v \varepsilon$ & •r درصد سبوس + آنزيم. \\
\hline$r \Delta / .9$ & N/NFI & Q/DIT & D/9TD & $4 / 1.1$ & r/VQs & $1 / r$ q & اشتباه معيار ميانكين \\
\hline \multicolumn{8}{|c|}{ سطوح معنى دارى } \\
\hline 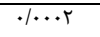 & $.1 \cdot 1.9$ & .1 .099 &.$/ . \wedge T \Delta$ &.$/ \cdot r I f$ &.$/ .+A T$ &.$/$. THQ & أنزيم \\
\hline . *rq & $.1 . .19$ &.$|\cdots|$ & $\cdot 1 \cdots \Delta$ & . MTIT & $\cdot / \ldots+$ &.$/ . r t$ & سبوس \\
\hline.$/ V V M A$ & $\cdot / \cdot v \wedge$ & . MTEY & . /9Ft. &.$/ F q \varepsilon$. &.$/ 49 V 1$ &. $\mid$. 481 & آنزيم × سبوس \\
\hline
\end{tabular}


جدول ه- ضريب تبديل خوراك جوجهها در هفتهاى مختلف و كل مدت آزمايش (جوجه/ كرم) Table 5. FCR of chicks during the different weeks and entire experimental period (chicken / g)

\begin{tabular}{|c|c|c|c|c|c|c|c|}
\hline \multicolumn{8}{|c|}{ اثر آنزيم } \\
\hline كل دوره - كل كل & هفته ششم & هفته ينجم & هفته جهارم & 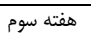 & هغنه دوم & هفته اول & \\
\hline $1 / 99^{a}$ & ITYN/QY & $T / T V$ & $1 / 9 \Delta$ & $r / r \Delta$ & 1/N9 & $1 / 49$ & صفر \\
\hline $1 / 9 Y^{0}$ & ITTD/Tr & T/M & V/AV & $r / r$. & $1 / v 1$ & $1 / F r$ & هـ|• مرصد \\
\hline.$/ . r 1$ & .1 .49 & . & 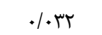 &.$/ \circ$. & 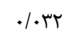 &.$/ . r \Lambda$ & اشتباه معيار ميانكين \\
\hline \multicolumn{8}{|c|}{ اثر سبوس } \\
\hline $1 / \lambda r^{c}$ & $1 / 99^{\circ}$ & $1 / 9 r^{0}$ & $T / A V^{0}$ & $T / T V$ & $1 / V^{0}$ & $1 / \mathbb{F}^{0}$ & صفر \\
\hline $1 / 99^{0 \mathrm{CO}}$ & $1 / \Lambda \Delta^{a}$ & $r / \mu^{\text {a }}$ & $1 / \Lambda \Delta^{\circ}$ & $T / T F$ & $1 / 99^{\circ}$ & $1 / 4 \kappa^{0}$ & •ا درصد \\
\hline $1 / q \mu^{\mathrm{bc}}$ & $1 / A r^{a}$ & $r / r^{a}$ & $|/ \Lambda|^{D}$ & T/RG & $1 / 9 \kappa^{D}$ & $1 / 4 F^{D}$ & هادرصد \\
\hline$r / \wedge^{a}$ & $1 / 91^{a}$ & $r /\left.c^{a}\right|^{a}$ & $r / I^{\mathrm{a}}$ & 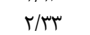 & $1 / 9 \cdot{ }^{a}$ & $\left.\left.||\right|^{a}\right|^{a}$ & . بروصد. \\
\hline.$/$. &.$/ \% r$ &.$/ . \Delta S$ & $.1 .+\Delta$ &.$/ \cdot v 1$ &.$/ .4 \Delta$ & .1 .49 & اشتباه معيار ميانكَين \\
\hline \multicolumn{8}{|c|}{ اثر متقابل أنزيم × سبوس } \\
\hline $1 / A F$ & $1 / 9 D$ & $1 / 94$ & $1 / 91$ & $T / \& \Delta$ & $1 / / \mathrm{V}$ & $1 / \times 9$ & يا پايه بدون سبوس \\
\hline$r / \cdot 1$ & $1 / M$ & $r / \% q$ & 1/q. & $r / \mu)$ & I/VY & $1 / \uparrow \Delta$ & •ا درصد سبوس \\
\hline 1/9v & 1/19 & $r / \% \Delta$ & $1 / \Lambda 1$ & $T / T V$ & $1 / \Delta q$ & $1 / 49$ & هادرصد سبوس \\
\hline$r / M r$ & $1 / 9 \pi$ & $T / \mu F^{2}$ & $r / r)$ & $T / T V$ & 1/9r & $1 / \Delta \Lambda$ & • ب درصد سبوس \\
\hline I/Ar & $1 / r^{\mu}$ & $1 / 91$ & I/Af & $r /$. & 1/99 & $1 / 4 F$ & بدون سبوس+آنزيم \\
\hline 1/91 & $1 / \Lambda$. & T/KF & $1 / \Lambda 1$ & $r / / \varphi$ & $1 / 94$ & $1 / 4 r$ & • إدرصد سبوس+|آنزيم. \\
\hline 1/19 & $1 / v \wedge$ & r//r & $1 / \Lambda 1$ & T/T & 1/99 & $1 / 4 r$ & ها درصد سبوس++آنزيم \\
\hline$r / . \Delta$ & $1 / 19$ & 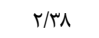 & $r / .1$ & $r / r q$ & I/AV & 1/9r & • ب درصد سبوس+آنزيم \\
\hline 更 &.$/ \%$ re & r & ו ו & 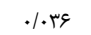 &.$/ .4 \Lambda$ & $. / . r \mid$ & اشتباه معيار ميانكين \\
\hline \multicolumn{8}{|c|}{ سطوح معنى دارى } \\
\hline 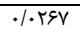 & . /rq१q & $.1 .9 \mathrm{YV}$ & $.1 .9 Q Y$ & $\cdot / . \Delta M$ &.$/$ TQV &.$/ 9440$ & أنزيم | لمي \\
\hline \% nr &.$\cdot .18$ &.$/ \ldots 1$ & 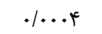 & D/AYG. &.$/ . \cdot T V$ &.$/ 1 \mathrm{MS}$ & سبوس - مس \\
\hline.$/ 91 \mathrm{wr}$ &.$/ 4199$ &.$/ \Delta \& V q$ & ג ג &.$/ F \cdot T r$ &.$/ 4 \cdot 19$ & . /Apqr & آنزيم × سبوس \\
\hline
\end{tabular}

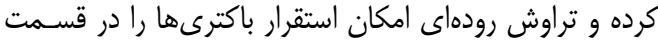

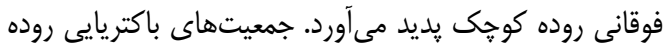

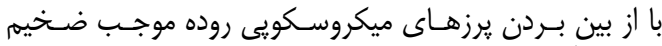

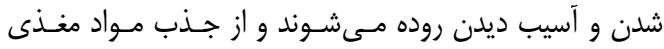

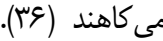

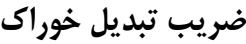

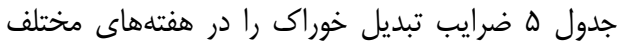

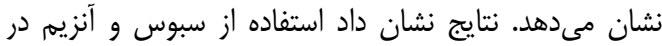

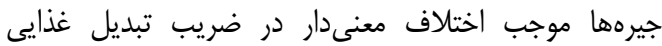

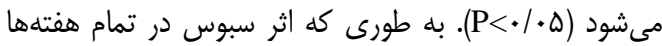

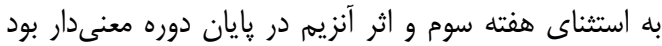

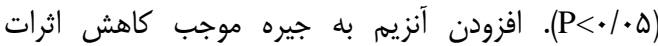

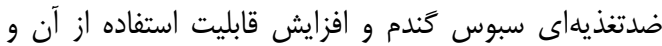

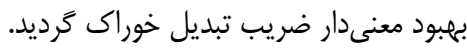

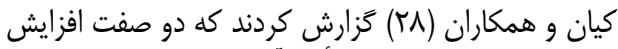

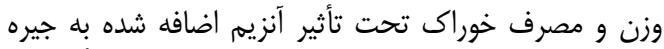

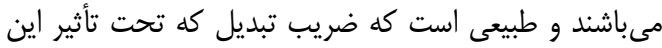

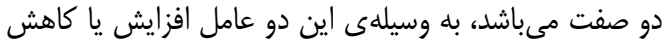

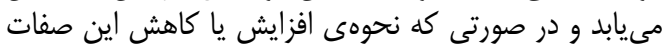

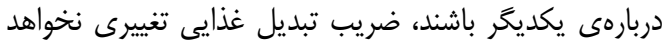

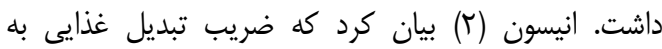

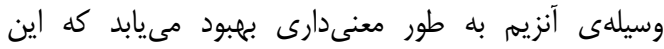

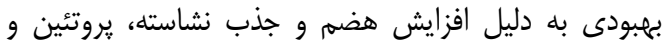

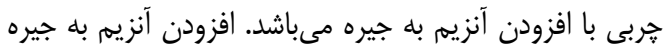

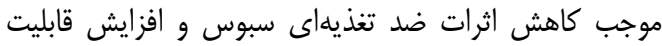

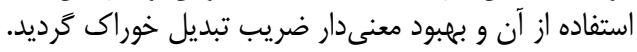

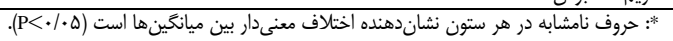

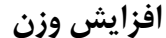

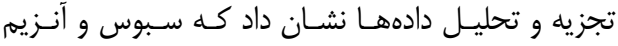

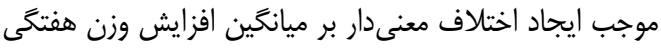

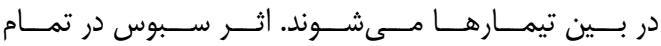

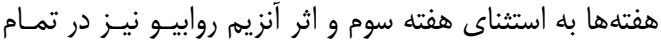

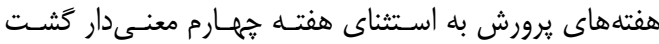

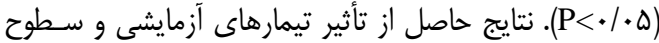

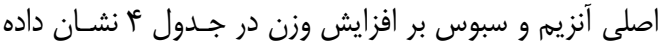

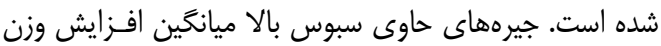

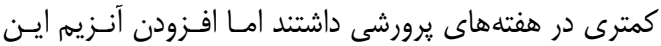

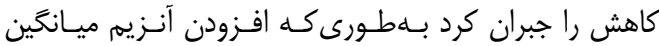

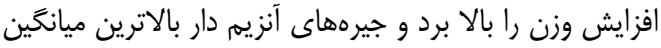

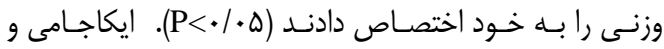

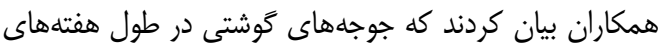

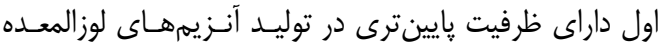

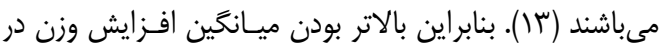

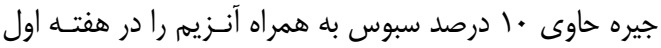

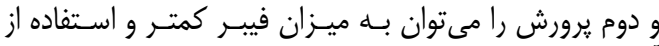

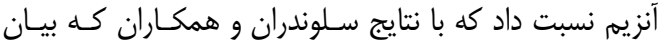

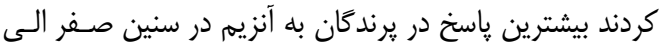

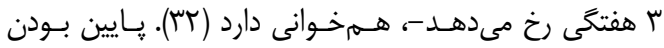

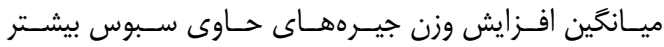

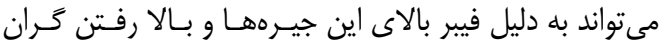

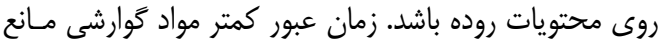

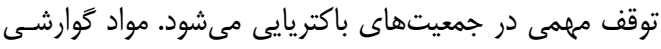

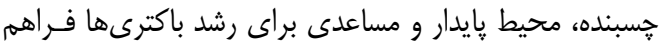


اختلاف معنى دارى وجود ندارد. تيمار حاوى ها داريم درصد سبوس

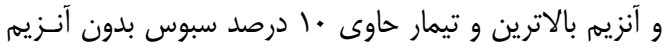

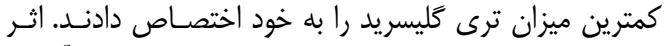

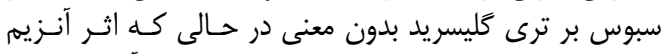

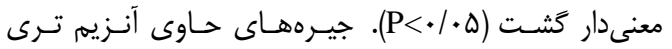

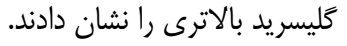
غلظت كلسترول خون

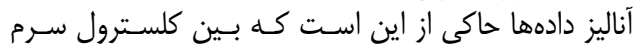

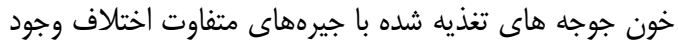

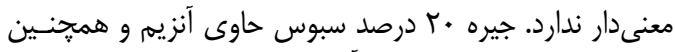

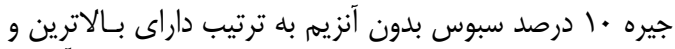

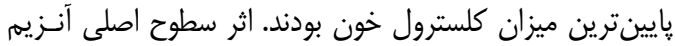

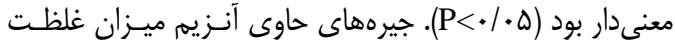

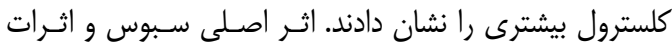
متقابل معنى دار نبود.

\section{غلظت HDL خون}

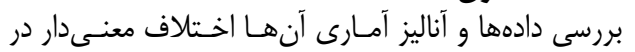

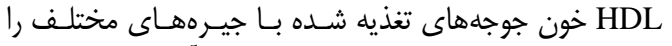

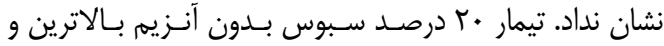

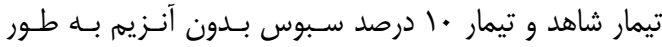

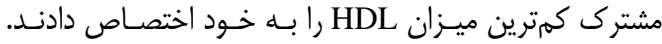

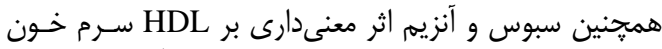

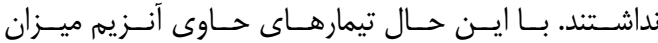

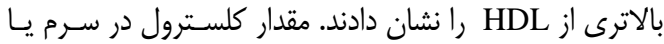

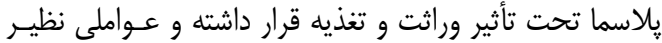

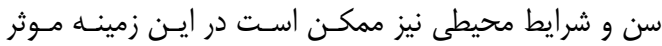

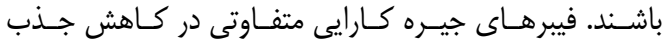

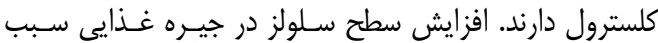

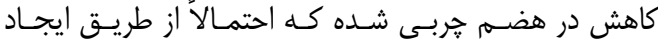

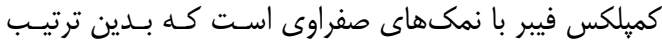

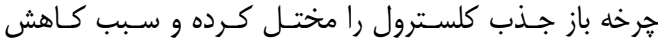

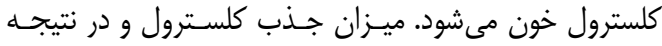

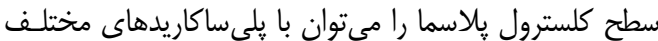

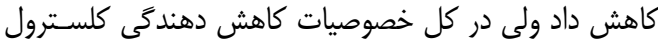

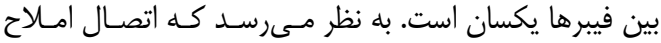

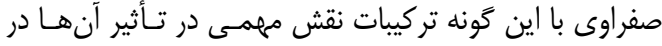

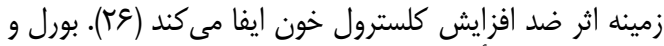

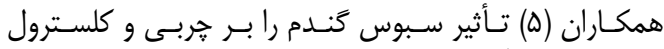

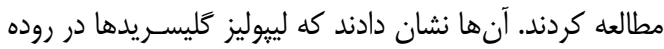

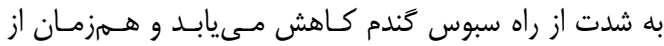

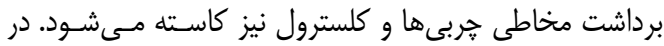

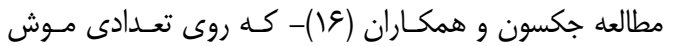

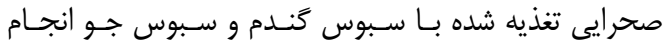

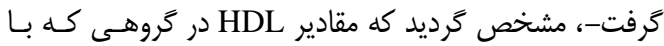

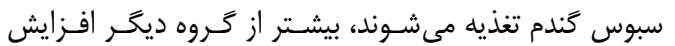

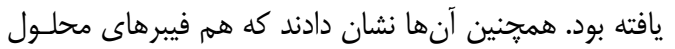

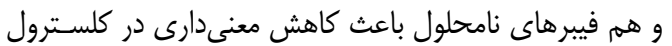

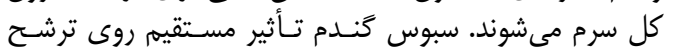

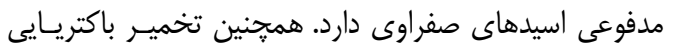

غلظت كَلوكز خون

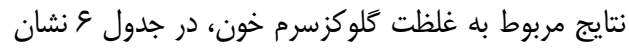

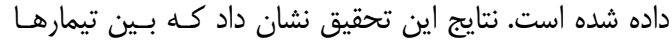

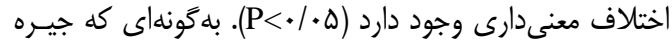

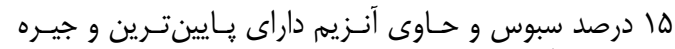

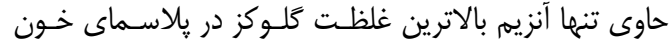

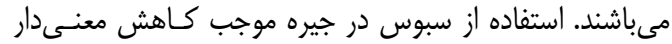

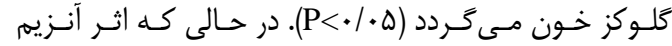

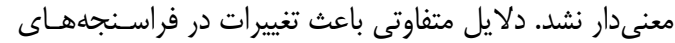

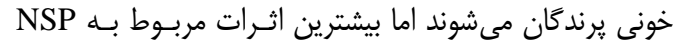

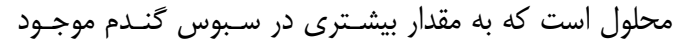

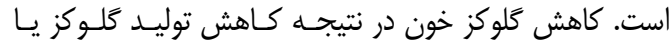

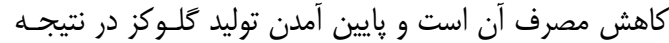

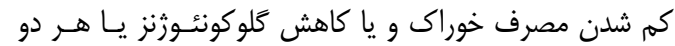

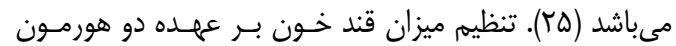

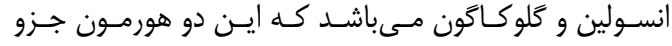

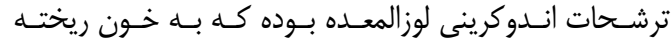

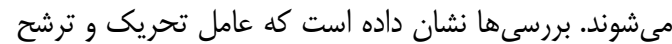

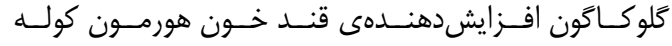

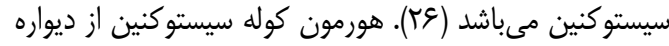

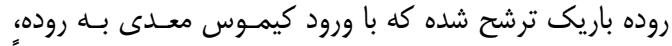

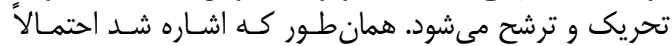

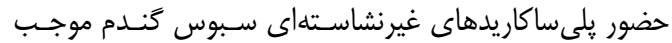

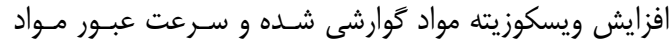

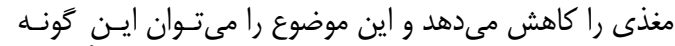

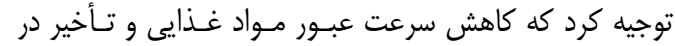

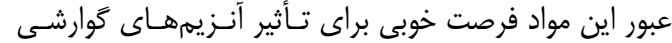

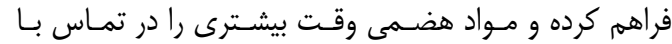

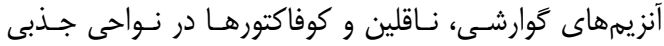

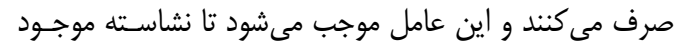

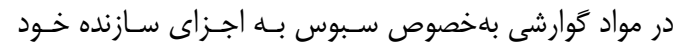

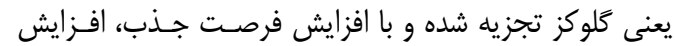

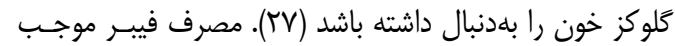

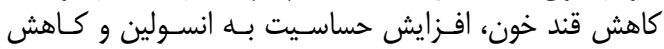

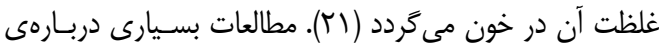

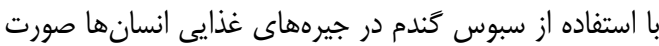

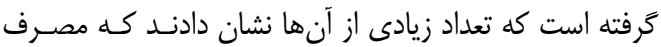

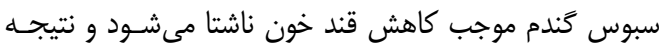

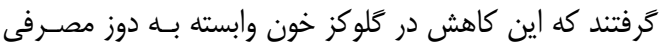

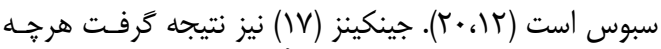

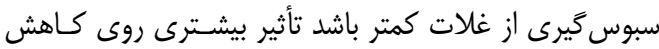

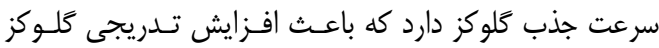

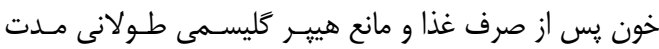

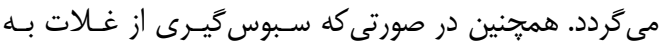

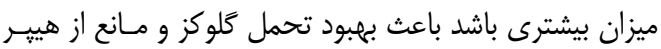

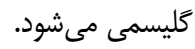
غلظت ترى كَليسر ميد خون

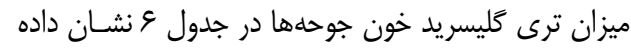
شده است. تجزيه و تحليل دادهها نشان داد كـهـ بـين تيمارهـا 
است. هرجند اين اختلافها به جز در مورد عنصر روى معنى دار نبوده است.

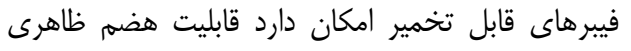

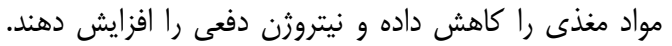

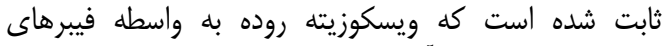

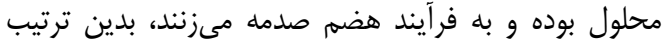

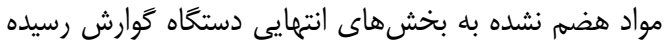

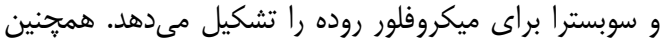

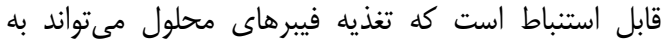

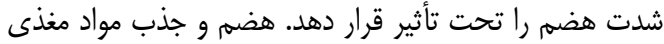

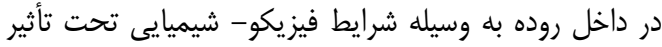

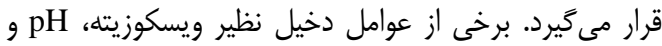

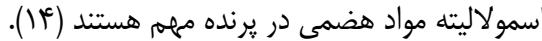

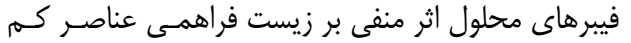

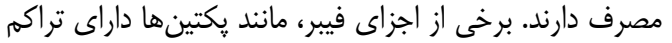

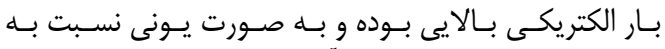

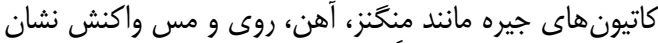

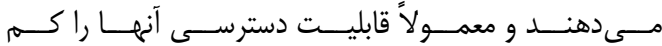

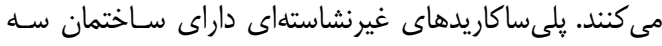

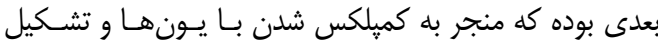

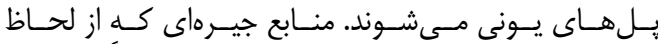

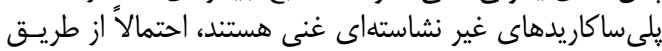

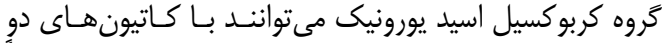

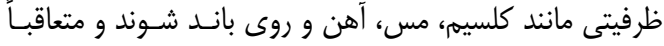

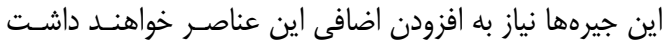

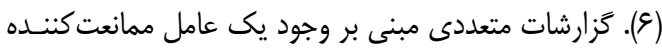

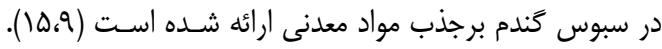

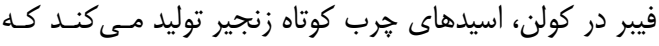

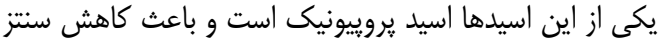

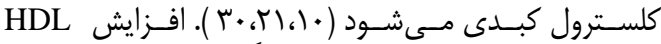

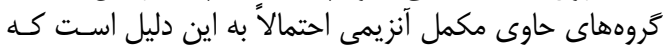

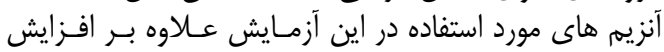

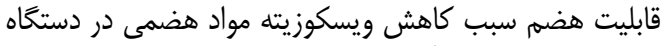

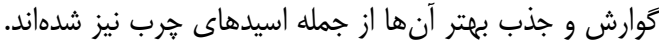

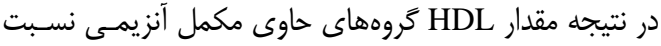

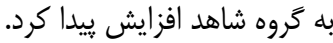
مواد معدنى خون آناليز داده ها نشان دون داد كه جيرههاى آزمايشى اختاف آناف

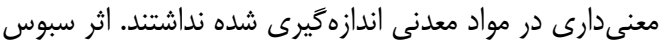

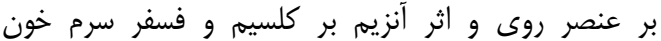

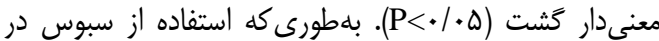

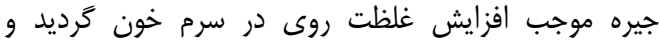

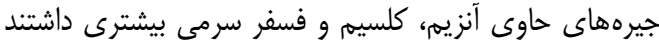

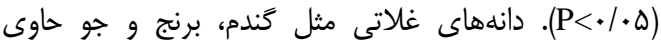

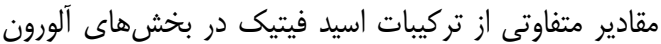

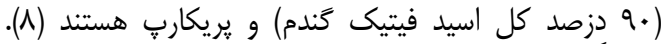

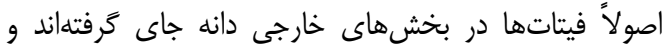

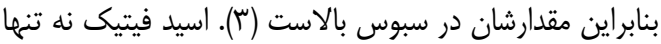

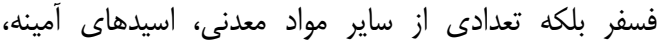

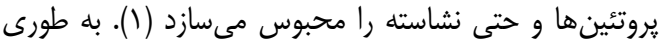

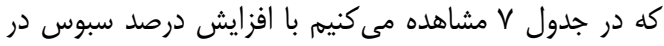

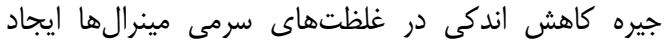

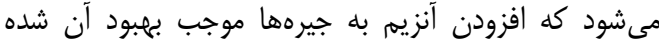


Table 6. Average serum concentrations of glucose and lipids (mg/dL)

\begin{tabular}{|c|c|c|c|c|}
\hline \multicolumn{5}{|c|}{ اثر آنزيم } \\
\hline HDL & كلسترول & ترى گليسريد & كلوكز & \\
\hline$q \cdot / v \Delta$ & $\| \widetilde{m} / \& \Lambda^{b}$ & $\mathrm{FV} / \cdot \mathrm{r}^{\mathrm{b}}$ & TVY/.9 & صفر \\
\hline १)/६ब & $\mid \Delta N / 1 \Delta^{\mathrm{a}}$ & $s V / V \Lambda^{a}$ & TVT/GN & ه./• درصد \\
\hline r/lrq & $r / 109$ & $F / \Delta \mid$ & $1 / 4 V$ & اشتباه معيار ميانگين \\
\hline \multicolumn{5}{|c|}{ اثر سبوس } \\
\hline $9 \cdot 10$. & $|0| / 0$. & $9 . / 11$ & $\mathrm{rMN} / \mathrm{A})^{\mathrm{a}}$ & صفر \\
\hline $19 / 84$ & $|F T / A|$ & $\Delta T / V \Delta$ & $r V T / r \Delta^{b}$ & ما درصد. \\
\hline MN/F & $\mid 19 q / \cdot 9$ & gr/lt & $r G T / r \Delta^{c}$ & ها درصد \\
\hline$१ ९ / r \Delta$ & $10 \cdot / \pi \mid$ & $\Delta r / \Delta S$ & $r \varepsilon \Delta / r \Delta^{c}$ & 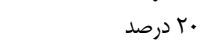 \\
\hline$r / 11$ & $F / \notin \notin \Lambda$ & s/rvq & $1 / 1+$. & اشتباه معيار ميانگين \\
\hline \multicolumn{5}{|c|}{ اثر متقابل آنزيم × سبوس } \\
\hline N\&/TV & IFT/Tr & $\Delta H / T \Delta$ & $r \wedge V / r \Lambda^{a}$ & קايه بدون سبوس \\
\hline$\Lambda \varepsilon / T r$ & 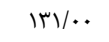 & ET/VQ & $r V \cdot / r \Delta^{b c}$ & •ا درصد سبوس \\
\hline$\Lambda V / V \Delta$ & ||$q \mid \ldots$ & $r q / r v$ & $r g V / \ldots c$ & ها درصد سبوس \\
\hline $1 \cdot r / \Delta \cdot$ & (ro/rv & Ft/VQ & $r G / V \Delta^{c d}$ & •r درصد سبوس \\
\hline qF/\& & $19 \cdot 194$ & SV/IT & $r q \cdot / r \omega^{\mathrm{a}}$ & بدون سبوس+آنزيم \\
\hline $9 r / M$ & $\mid Q F / G T$ & ST/VD & $T V G / T \Delta^{b}$ & •ا درصد سبوس+آنزيم \\
\hline ^9/1 & LOT/TK & VG/AV & $r \Delta V / \Delta^{d}$ & ها درصد سبوس+آنزيم \\
\hline$q \cdot 1 \cdots$ & $\mid \varepsilon \Delta / T \Delta$ & $g r / T r$ & $r G 9 / V D^{c}$ & •r درصد سبوس+أنزيم \\
\hline $1 / 8$. & $r / \Lambda)$ & $\mu / \uparrow \wedge$ & $r / \cdot \Lambda$ & اشتباه معيار ميانخين \\
\hline \multicolumn{5}{|c|}{ سطح معنىدارى } \\
\hline.$/$ V991 & . $/ \cdots r$ &.$/ \cdot M f$ & - Mfift & أنزيم \\
\hline ./TMM9 & 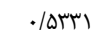 & $\cdot 19 \cdot 49$ & $.1 \cdots+1$ & سبوس \\
\hline .1 .197 & $\cdot / \pi \cdot 9 \cdot$ & $\cdot / 9 \cdot r$. & $.1 \cdot \mathrm{rgV}$ & آنزيم × سبوس \\
\hline
\end{tabular}

جدول V- ميانحَين غلظت مواد معدنى سرم خون (ميلى گرم /دسى ليتر) Table 7. Average serum concentrations of minerals (mg/dL)

\begin{tabular}{|c|c|c|c|c|c|c|}
\hline \multicolumn{7}{|c|}{ اثر آنزيم } \\
\hline روى & مس & منيزيوم & أهن & فسفر & كلسيم & \\
\hline$r \Delta T / T \Delta$ & GM/IT & r/at & $1+9 / v 1$ & $\Delta / q^{D}$ & $q / K r^{D}$ & صفر \\
\hline TEV/SD & $\Delta Q / \Delta Q$ & $r / V V$ & $\| Q / E Y$ & $V / I r^{\mathrm{a}}$ & $1 \cdot / \mathbb{e r}^{\mathrm{a}}$ & ه•|• درصد \\
\hline g/Vef & f/Dqf & $\cdot 1 \cdot \Delta$. & $r / I G T$ & ./TAV & . & اشتباه معيار ميانخين \\
\hline \multicolumn{7}{|c|}{ اثر سبوس } \\
\hline$r \cdot q / .^{0}$ & fq/gr & T/\&A & $1.9 / 94$ & $9 / 99$ & $9 / \mathrm{V} \wedge$ & صفر \\
\hline$r \Delta S / \Lambda r^{\mathrm{a}}$ & $\Delta S / \Delta$. & r/Ar & $\| f / M$ & $9 / 11$ & $q / V r$ & •ا درصد. \\
\hline rดq/qua & $q \mu$ & $r / 9 \varphi$ & $\| F / \& \Lambda$ & g/TV & १/^९ & ها درصد \\
\hline$r V G / V \Delta^{a}$ & SN/TI & $r / \varnothing \varnothing$ & $11 \% / \ldots$ & $q|9|$ & $9 / 94$ & . F درصد \\
\hline Q/DHA & g/sqf & $\cdot 1 \cdot \mathrm{n}$ & $\%$ \%. & $\cdot / / \cdot \Delta$ & $\cdot / 4 \wedge$. & اشتباه معيار ميانگين \\
\hline \multicolumn{7}{|c|}{ اثر متقابل آنزيم × سبوس } \\
\hline$r+\Delta / / T$ & $c q / \Delta$. & $T / \Delta \Lambda$ & $11 \cdot / r \Delta$ & $9 / \cdot 1$ & N/A & يايه بدون سبوس \\
\hline$r \Delta \cdot / \Lambda V$ & $\Delta Q / T \Delta$ & r/AT & $1 \cdot N / A V$ & $\Delta / \Gamma$. & N/A & •ا درصد سبوس. \\
\hline$r V / \Delta$. & $V \cdot / V \Delta$ & $T / \Delta V$ & $110 / T V$ & $\Delta / \Lambda \varepsilon$ & $9 / \% q$ & ها درصد سبوس \\
\hline TAT/D. & $\mathrm{V} / /$. & $T / \Delta V$ & $1+r / g r$ & g/Fr & $9 / 91$ & •r درصد سبوس \\
\hline rIT/AV & $r q / v \Delta$ & $T / V$ & $1.9 / 84$ & V/ar & $1 \cdot / n 1$ & بدون سبوس+آنزيم \\
\hline rEI/rV & $\Delta V / V \Delta$ & r/AT & $119 / 0$. & $\mathrm{V} / \cdot \mathrm{V}$ & $1 \cdot / \Delta \Lambda$ & •ا درصد سبوس +آنزيم \\
\hline TEg/TV & $\Delta \Delta / T \Delta$ & $T / V \Delta$ & $114 \%$ & $8 / 8 \wedge$ & $1 . / 4 V$ & ها درصد سبوس+آنزيم \\
\hline$r V \cdot 1 .$. & $\Delta Q / g r$ & $r / v g$ & $119 / \mathrm{TV}$ & s/A. & १/१ & • ب درصد سبوس+آنزيم \\
\hline g/me. & r/rqם & .1 .4$. & $1 / 81$. & . &.$/ K F$. & اشتباه معيار ميانگين \\
\hline \multicolumn{7}{|c|}{ سطح معنى دارى } \\
\hline$\cdot|\Delta \& M|$ & $\cdot /$ TAVA & .1 .901 &.$/ .9 \wedge \mu$ &.$/ . \cdot 91$ & .1 .199 & آنزيم \\
\hline r...r & . & 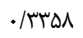 & $\cdot / 9 \Lambda \cdot r$ & . /DTTA &.$/ 9910$ & سبوس \\
\hline س & .10991 & - Metre & $\cdot / \Lambda \Lambda F V$ & 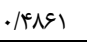 & | & آنزيم × سبوس \\
\hline
\end{tabular}




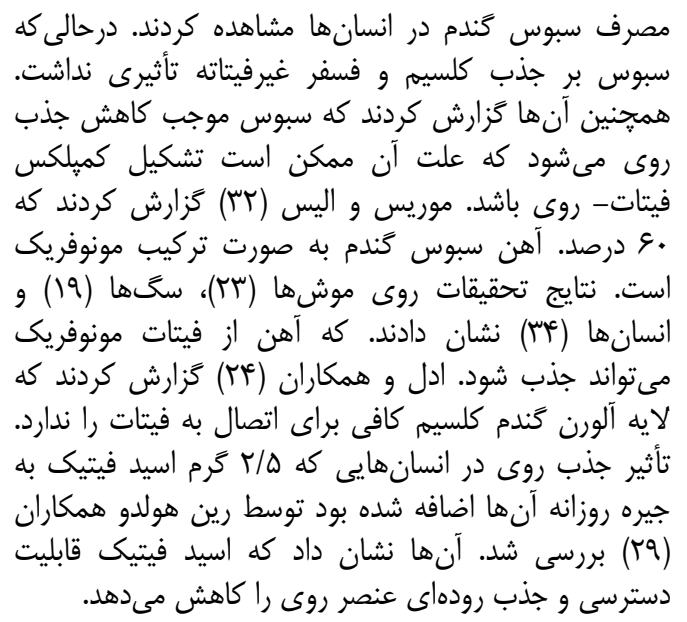

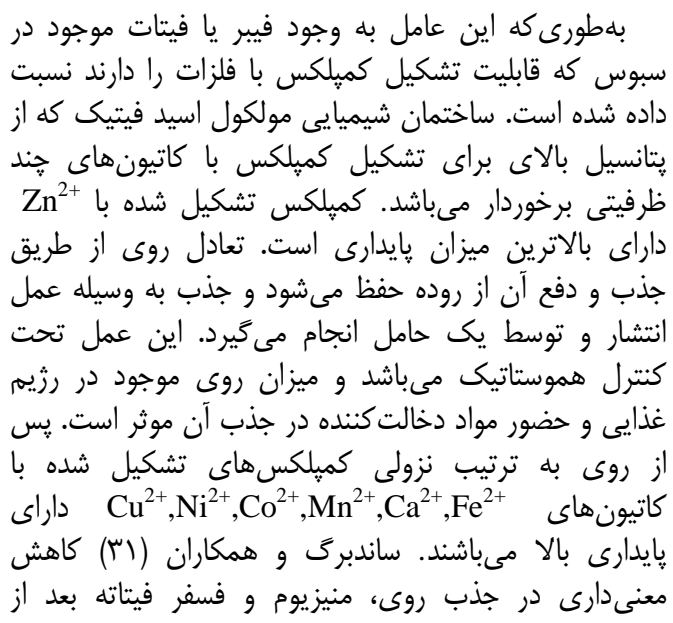

1. Afsharmazandaran, N. and A. Rajab. 2000. Application of enzymes in poultry nutrition, Publications of Nourbakhsh, 192 pp (In Persian).

2. Annison, G. 1992. Commercial enzyme supplementation of wheat-based diets raises ileal glycanase activities and improve apparent metabolisable energy, starch and pentosan digestibility in broiler chicks. Animal. Feed Science and Technology, 38: 105-121.

3. Bartnik, M. and T. Jakubczyk. 1989. Chemical composition and the nutritive value of wheat bran. Bourne GH (ed): Nutritional value of cereal products, Beans and starches. World reviewsnatural. Diet. Basel, Karger, 60: 92-131.

4. Bedford, M.R., J.F. Patience, H.L. Classen and J. Inborr. 1992. The effect of dietary enzyme supplementation of rye and barley-based diets on digestion and subsequent performance inweanling pigs. Animal Science, 72: 97-105.

5. Borel, P., D. Lairon, M. Senft, M. Chautan and H. Lafont. 1989. Wheat bran and wheat germ: effect on digestion and intestinal absorption of dietary lipids in the rat. The American Journal of Clinical Nutrition, 49: 192-202.

6. Brenes, A., M. Smith, W. Guenter and R.R. Marquardt. 1993. Effects of enzyme supplementation on the performance and digestive tract size of broiler chickens fed wheat and barley-based diets. Poultry Science, 72: 1731-1739.

7. Brillouet, J.M., J.P. Joseleau, J.P. Utille and D. lelievre. 1982. lsolation purification and characterization of a complex heteroxylan from in dustrial wheat bran. Agriculture food chemical, 30 : 488-495.

8. Clarence, B., D. Ammerman and J.L. Austin. 1995. Bioavailability of nutrients for Animals Amino acids, Minerals and vitamins. Edited by New York: Academic Press, 12 pp.

9. Davies, N.T. and S.E. Olpin. 1979. Studies on the phytate: zinc molar contents in diets as a determinant of $\mathrm{Zn}$ availability to youmg rats British Journal of Nutrition, 41: 591.

10. Frans, M.J. 2000. Nutritional care in diabetes mekkutys in: Mahan LK, Escott-stupm S, editors. Food, Nutritional and diet therapy, $10^{\text {th }}$ ed, New York, raven press, 681-713.

11. Gutierrez del Alamo, A., M.W.A. Verstegen, A. Den Hartog, P. Perez de Ayala and M.J. Villamide. 2008. Effect of wheat cultivar and enzyme addition to broiler chicken diets on nutrient digestibility, performance, and apparent metabolizable energy content. Poultry Science, 87: 759-767.

12. Hollenbeck, C.B., A.M. Coulston and G.M. Reaven. 1986. To what extent does increased dietary fiber improve glucose and lipid metabolismin patients with noninsulin-dependent diabetes mellitus (NIDDM). The American Journal of Clinical Nutrition, 43: 16-24.

13. Ikegami, S., F. Tsuchihashi, H. Harada, W. Tsuchihashi, E. Nishide and S. Innami. 1990. Effect of viscous indigestible polysaccharides on pancreatic-biliary secretion and digestive organs in rats. Journal of Nutrition, 120: 353-360.

14. Isaksson, G., I. Lundquist and I. Ihse. 1989. Effect of dietary fiber on pancreatic enzyme activity in vitro. The importance of viscosity, $\mathrm{PH}$, ionic strength, absorption and time of incubation. Gastroenterology, 82: 918-924. 
er. تأثير آنزيم روابيو بر عملكرد رشل، برخى متابوليتهاى خون و قابليت جذب عناصر

15. Ismail-Beigi, f., B. Faraji and J.G. Reinhold. 1977. Binding of zinc and iron to wheat breed. Wheat bran. And their components. The American Journal of Clinical Nutrition, 30: 17-21.

16. Jackson, K.A., D.A. Suter and D.L. Topping. 1994. Oat brane, barley ower plasma cholesterol relative toeheat bran but differs in their effects on liver cholesterol in rats fed diets with and without cholesterol. Journal of Nutrition, 124: 1678-84.

17. Jenkis, D.J., M. Axelsen, C.W. Kendall, L.S. Augustin, V. Vulsa and U. Smith. 2000. Dietary fiber, lent carbohydrates and the insulin-resistant diseases. British Journal of Nutrition, 83: 57-63.

18. Kamyab, A. and M. Houshmand. 2004. The effect of multi-enzyme in wheat and barley based diets on broiler performance. Australian Poultry Science Symposium, 16: 80-83.

19. Lipschitz, D.A., K.M. Simpson, J.D. Cook and E.R. Morris. 1979. Absorption of monoferric phytate by dogs. Journal of Nutrition, 109: 1154-1160.

20. Manhire, A., C.L. Henry, M. Hartog and K.W. Heaton. 1981. Unrefined carbohydrate and dietary fiber in treatment of diabetes mellitus. Journal of Human Nutrition and Dietetics, 35: 99-101.

21. Meyer, K.A., L.H. Kushi, D.R. Lacobs, J. Salivan, A. Sallers and A.R. Folsom. 2000. Carbohydrates dietary fiber and incident type 2 diabetes in older women. The American Journal of Clinical Nutrition, 71: 921-930.

22. Moharry, A. 2006. Comparison of performance and digestibility characteristics of broiler fed diets containing treated hulled barley or hulless barley. Animal Science, 51: 122-131.

23. Moorris, E.R. and R. Ellise. 1976. Isolation of monoferirc phytate from wheat bran and its biological value as an iron source to the rat. Journal of Nutrition, 106: 753-760.

24. Odell, B.1., C.E. Burpo and J.E. Savage. 1972. Evaluation of zinc availability in foodstuffs of plant and animal origin. Journal of Nutrition, 102: 653-660.

25. Ozek, K., O. Yazgan and Y. Bahtiyarca. 2003. Effects of dietary protein and energy concentrations on performance and carcass characteristics of chukar partridge (Alectoris Chukar) raised in captivity. Poultry Science, 44: 419-426.

26. Panahidehghan, M.R., S. Negadfriduni, R. Zenderuhkermani, M. Modirsanei, M. Moafimahmudabadi, S.M. Mirsalimi and F. Niknafas. 1995. Physiology of birds (translatation). Department of Agriculture, Economic, education and research, pp: 689 (In Persian).

27. Poorreza, G., GH. Sadeghi and M. Mehri. 2006. Feeding birds (translation). Second edition. Publications of Arkan Danesh. Esfahan, 672 pp (In Persian).

28. Qian, H., E.T. Kornegay and D.M. Denbow. 1997. Utilization of phytate phosphorus and calcium as influenced by microbial phytase, cholecalciferol and the calcium: total phosphorus ratio in broiler diets. Poultry Science, 76: 37-46.

29. Reinhold, J.G. 1972. Phytate concentrations of leavened and un leavened Iranian breeds. Ecology of Food and Nutrition, 1: 187-192.

30. Salmeron, J., J.E. Manson, M.J. Stampfer, G.A. Colditz and A.L. Wing. 1997. Dietary fibre glycemic load, and risk of non-insulin-dependent diabetesmellitus in women Journal of the American Medical Association, 277: 472-477.

31. Sandberg, A., C. Hasselblad and K. Hasselbled. 1982. The effect of wheat bran on the absorption of minerals in the small intestine British Journal of Nutrition, 48: 185-191.

32. Selvendran, R.R., B.J. Stevens and M.S. Dupont. 1987. Dietary fiber. Chemistry, analysis and properties. Advanced Food Research, 31: 117-209.

33. Senkoylu, N., H. Akyurek and H.E. Samali. 2004. Implications of b-glucanase and pentosanase enzymes in low-energy low-protein barley and wheat based broiler diets. Animal science, 49: 108-114.

34. Simpson, K.M., E.R. Morris and J.D. Cook. 1981.The inhibitory effect of bran on iron absorption in man. The American Journal of Clinical Nutrition, 34: 1469-1478.

35. Smits, C.H.M. 1996. Viscosity of dietary fibre in relation to lipid digestibility in broiler chicken. Phd Thesis, Agriculture. University Wageningen, the Netherlands, $140 \mathrm{pp}$.

36. Wang, Z.R., S.Y. Qiao, W.Q. Lu and D.F. Li. 2005. Effect of enzyme supplementation on performance, nutrient digestibility gastrointestinal morphology and volatile fatty acid profiles in the hindgut of broilers fed wheat-based diets. Poultry Science, 84: 875-881.

37. Yousefpour, M. 2001. Investigation on the effect of multienzyme supplementation in wheat and barley-based diets on broiler performance. This is submitting for the degree of Master of Science department of animal science, Islamic Azad University. Karaj, 272 pp (In Persian). 


\title{
Effect of Revabio in Diets Containing Wheat Bran on Growth Performance, Some Blood Metabolites and Absorbing of Mineral Elements in Broilers Chickens
}

\author{
Somayeh Daymeh ${ }^{1}$, Nazar Afzali ${ }^{2}$ and Moslem Bashtani ${ }^{2}$ \\ 1- Graduated M.Sc., University of Birjand \\ (Corresponding author: s_daymeh@yahoo.com) \\ 2- Associate Professor, University of Birjand \\ Received: July 14, $2012 \quad$ Accepted: May 24, 2014
}

\begin{abstract}
In this research, influence of Revabio enzyme on improving anti-nutritional of wheat bran (high in fiber, non-starch polysaccharides and phytate) were investigated. The total number of 320 commercial male broiler chicks (Ross 308 ) in a factorial experiment $4 \times 2$ with four replications were used. Treatment consists of four levels of wheat bran $(0,10,15$ and 20 percent) and two levels of enzyme ( 0 and 0.05 percent), respectively. The experiment was carried on 42 days and divided into 3 period of starter, grower and finisher. Feed intake, body weight gain and feed conversion ratio (FCR) were determined for each week of experiment. In day 42, 2 birds from each unit were slaughtered and blood sampling was taken. The results showed that including wheat bran in the diets had no significant effect on weight gain and feed conversion ratio in total period. With increasing wheat bran levels, the average of weight gain was decreased. Adding enzyme to diets significantly improved weight gain and feed conversion ratio. The use of wheat bran in the diet reduced blood glucose and incresed zinc consentration significantly $(\mathrm{P}<0.05)$ but did not significant effect on other serum parameters. Revabio increased serum concentrations of triglyceride, cholesteroand significantly $(\mathrm{P}<0.05)$. Also Chicks fed with enzyme had higher serum concentrations of calcium, phosphorus consentration. Results of this experiment showed that, addition of enzyme on diets can improve anti nutritional of wheat bran and use wheat bran as part of diets in broiler diets.
\end{abstract}

Keywords: Blood metabolites, Broiler, Performance, Revabio, Wheat bran 